\title{
Handling equipment Selection in open pit mines by using an integrated model based on group decision making
}

\author{
Abdolreza Yazdani-Chamzini ${ }^{{ }^{*}}$ and Siamak Haji Yakhchali ${ }^{\text {b }}$
}

${ }^{a}$ Young Researchers Club, South Tehran Branch, Islamic Azad University, Tehran, Iran

${ }^{b}$ Assisstance professor of Tehran University, Department of Industrial Engineering, College of Engineering, University of Tehran, Tehran, Iran ARTICLEINF O ABSTRACT

\section{Article history:}

Received 25 January 2012

Received in revised form

April, 5, 2012

Accepted April 82012

Available online

11 April 2012

Keywords:

Handling Equipment selection

FAHP

FTOPSIS

Group decision making

\begin{abstract}
Process of handling equipment selection is one of the most important and basic parts in the project planning, particularly mining projects due to holding a high charge of the total project's cost. Different criteria impact on the handling equipment selection, while these criteria often are in conflicting with each other. Therefore, the process of handling equipment selection is a complex and multi criteria decision making problem. There are a variety of methods for selecting the most appropriate equipment among a set of alternatives. Likewise, according to the sophisticated structure of the problem, imprecise data, less of information, and inherent uncertainty, the usage of the fuzzy sets can be useful. In this study a new integrated model based on fuzzy analytic hierarchy process (FAHP) and fuzzy technique for order preference by similarity to ideal solution (FTOPSIS) is proposed, which uses group decision making to reduce individual errors. In order to calculate the weights of the evaluation criteria, FAHP is utilized in the process of handling equipment selection, and then these weights are inserted to the FTOPSIS computations to select the most appropriate handling system among a pool of alternatives. The results of this study demonstrate the potential application and effectiveness of the proposed model, which can be applied to different types of sophisticated problems in real problems.
\end{abstract}

\section{Introduction}

Equipment selection plays a key role in mining design due to the fact that an inappropriate selection can negatively affect the overall cost and continuity of a mine. Loading and handling equipment are among the most crucial operation impacting production in surface and underground mines and have a substantial share of a total mine costs (Sayadi et al., 2012). Material handling can account for 30-75\% of the total cost, and efficient material handling can be primarily responsible for reducing the operating cost by 15-30\% (Sule, 1994; Kulak, 2005). Many tangible and intangible parameters influence the problem of the handling equipment selection; so that, these factors are often in conflicting with each other. Therefore, this problem is a multi-criteria decision making (MCDM) problem. Technique for Order Preference by Similarity to Ideal Solution (TOPSIS) (Hwang \& Yoon, 1981) is one of the most widely used in the MCDM issues. This method takes into consider the ideal and the anti-ideal solutions

* Corresponding author. Tel. +989132820820

E-mail: abdalrezaych@gmail.com (A. Yazdani) 
simultaneously. This technique has some unique advantages, including logical and simple computations as well as results are obtained in shorter time than other methods such as AHP (analytical hierarchy process) and ANP (analytic network process) (Fouladgar et al., 2011; Lashgari et al., 2011).

However, TOPSIS is often criticized for its inability to handle vague and uncertain problems (Yu et al., 2011); so that, without considering the inherent uncertainty and/or imprecision of the elements could result in unreliable and unrealistic assessment. On the other hand, fuzzy logic is capable to handle the existing uncertainty. This technique uses linguistic variable instead of traditional quantitative expression, which is a very helpful concept for dealing with situations which are too complex or not well-defined enough (Zadeh, 1965). According to Fouladgar et al. (2011), fuzzy TOPSIS (FTOPSIS) has different advantages, including logical concepts, simple and fast computations, and tolerating the uncertainty. This technique has been applied in different aspects of engineering and management problems, including business competition (Sun \& Lin, 2009; Torlak et al., 2011), strategic management (Fouladgar et al., 2011), risk assessment (Lai \& Chen, 2011; Fouladgar et al., 2012b), service quality (Awasthi et al., 2011), supply chain management (Liao \& Kao, 2011; Zouggari \& Benyoucef, 2012), equipment selection (Lashgari et al., 2011; Yazdani-Chamzini \& Yakhchali, 2012), energy planning (Moradi et al., 2011; Kaya \& Kahraman, 2011), and performance evaluation (Yu \& Hu, 2010; Bao et al., 2012). On the other hand, AHP (analytical hierarchy process) is the most popular technique in MCDM problems. This technique applies pair-wise comparison for calculating the weights of elements under consideration. AHP is strongly connected to human judgment and pairwise comparisons in AHP may cause evaluator's assessment bias which makes the comparison judgment matrix inconsistent (Aydogan, 2011). Therefore, fuzzy analytical hierarchy process (FAHP) is developed to solve the bias problem in AHP.

In this paper, an integrated approach based on FAHP and FTOPSIS is developed to solve MCDM problems in which the weights of evaluation criteria and the performance ratings of alternatives are calculated based on linguistics terms under group decision making. The importance weights of criteria are calculated by FAHP. Then, by applying the criteria weights obtained in the first step, FTOPSIS technique is employed to evaluate the handling equipment. Briefly, the relative weights of the evaluation criteria calculated by FAHP are entered into the FTOPSIS computations for selecting the best alternative. The remainder of this paper is organized as follows. Fuzzy set theory is presented in the next section. In section 3, FAHP method is summarized. Section 4 illustrates FTOPSIS method and explains the basic descriptions on the steps of the method. The proposed model is discussed in section 5. A case study is explained in section 6 to illustrate the potential application of the proposed method. A sensitivity analysis is conducted in section 7 . In the last section, conclusions are discussed.

\section{Fuzzy set theory}

Uncertainty is a major part of decision making problems in real world that is resulted from two areas (Fouladgar et al., 2011): (1) uncertainty in subjective judgments (2) uncertainty due to lack of data or incomplete information. The first is due to experts may not be $100 \%$ sure when making subjective judgments and the later is caused by sometimes information of some attributes may not be fully available or even not available at all. Modeling the uncertainty is very valuable so that it causes to reduce complexity and increases credibility of the resulting model. Fuzzy theory, introduced by Zadeh (1965), is a powerful tool to handle the existing uncertainty and the outputs be more precise, accurate, and reliable (Fouladgar et al, 2012a). A fuzzy set is defined by a membership function, which determines to each element a grade of membership within the closed interval 0 and 1 . Membership of 0 means that the value does not belong to set A, membership of 1 means that the value belong to the set under consideration, and membership anywhere between 0 and 1 determines the degree of membership (Fouladgar et al., 2012b). A triangular fuzzy number (TFN) can be denoted as $\tilde{A}=(l, m, u)$ and its membership function $\mu_{A}(x)$ can be defined as follows: 
$\mu_{A}(x)= \begin{cases}(x-l) /(m-l) & l \leq x \leq m, \\ (x-u) /(m-u) & m \leq x \leq u, \\ 0, & \text { otherwise }\end{cases}$

Where $l, m$, and $u$ stand for the lower, middle, and upper value of the support of $\tilde{A}$, respectively, and $l \leq m \leq u$.

Let $\tilde{A}=\left(a_{1}, a_{2}, a_{3}\right)$ and $\tilde{B}=\left(b_{1}, b_{2}, b_{3}\right)$ be two TFNs, the mathematical relations between $\tilde{A}$ and $\tilde{B}$ are as follows:

$$
\begin{aligned}
& \tilde{A}(\div) \tilde{B}=\left(a_{1}, a_{2}, a_{3}\right)(\div)\left(b_{1}, b_{2}, b_{3}\right)=\left(\frac{a_{1}}{b_{3}}, \frac{a_{2}}{b_{2}}, \frac{a_{3}}{b_{1}}\right) \\
& \tilde{A}(+) \tilde{B}=\left(a_{1}, a_{2}, a_{3}\right)(+)\left(b_{1}, b_{2}, b_{3}\right)=\left(a_{1}+b_{1}, a_{2}+b_{2}, a_{3}+b_{3}\right) \\
& \tilde{A}(-) \tilde{B}=\left(a_{1}, a_{2}, a_{3}\right)(-)\left(b_{1}, b_{2}, b_{3}\right)=\left(a_{1}-b_{3}, a_{2}-b_{2}, a_{3}-b_{1}\right) \\
& \tilde{A}(\times) \tilde{B}=\left(a_{1}, a_{2}, a_{3}\right)(\times)\left(b_{1}, b_{2}, b_{3}\right)=\left(a_{1} b_{1}, a_{2} b_{2}, a_{3} b_{3}\right) \\
& (\tilde{A})^{-1}=\left(\frac{1}{a_{3}}, \frac{1}{a_{2}}, \frac{1}{a_{1}}\right)
\end{aligned}
$$

The vertex method to calculate the distance between $\tilde{A}, \tilde{B}$ is defined as follows:

$$
d(\tilde{A}, \tilde{B})=\sqrt{\frac{1}{3}\left[\left(a_{1}-b_{1}\right)^{2}+\left(a_{2}-b_{2}\right)^{2}+\left(a_{3}-b_{3}\right)^{2}\right]}
$$

\section{FAHP Methodology}

Analytic Hierarchy Process (AHP) was first introduced by Satty (1980) that is a mathematical tool for solving the MCDM problems. AHP is frequently used to solve the multiple criteria decision making problems and has successfully been applied for many practical contexts (Ahari et al., 2011). AHP decomposes a complex decision problem into several levels in a structure of hierarchy and then calculates the weight of the factors with the pairwise comparison (Fouladgar et al., 2012c). For a matrix of order $n,((n) \times(n-1) / 2)$ comparisons are required. The fundamental scale used for this purpose is based on Saaty 1-9 scale.

AHP method is combined with fuzzy methodology by different researchers to solve the problem of the conventional AHP in handling uncertainty. Fuzzy sets can be used more appropriately in human's verbal and ambiguous descriptions and we should decide in real world by benefiting from fuzzy sets (Parsaei et al., 2012). For achieving the aim, a scale of $\tilde{1}-\tilde{9}$ can be defined for TFNs instead of the scale of $1-9$ as presented in Table 1.

\section{Table 1}

Membership function of linguistic variable

\begin{tabular}{lllll}
\hline Intensity of importance & Fuzzy number & Linguistic variable & Membership function & Reciprocal scale \\
\hline 9 & $\tilde{9}$ & Perfect (P) & $(8,9,10)$ & $(1 / 10,1 / 9,1 / 8)$ \\
8 & $\tilde{8}$ & Absolute (A) & $(7,8,9)$ & $(1 / 9,1 / 8,1 / 7)$ \\
\hline 7 & $\tilde{7}$ & Very good (VG) & $(6,7,8)$ & $(1 / 8,1 / 7,1 / 6)$ \\
6 & $\tilde{6}$ & Fairly good (FG) & $(5,6,7)$ & $(1 / 7,1 / 6,1 / 5)$ \\
5 & $\tilde{5}$ & Good (G) & $(4,5,6)$ & $(1 / 6,1 / 5,1 / 4)$ \\
4 & $\tilde{4}$ & Preferable (PR) & $(3,4,5)$ & $(1 / 5,1 / 4,1 / 3)$ \\
3 & $\tilde{3}$ & Not bad (N) & $(2,3,4)$ & $(1 / 4,1 / 3,1 / 2)$ \\
2 & $\tilde{2}$ & Weak advantage (W) & $(1,2,3)$ & $(1 / 3,1 / 2,1)$ \\
1 & $\tilde{1}$ & Equal (E) & $(1,1,1)$ & $(1,1,1)$ \\
\hline
\end{tabular}


The authors adopted Chang's extent analysis method (Chang, 1996) because the steps of this approach are relatively easier, less time taking and less computational expense than the other fuzzy AHP (Van Laarhoven \& Pedrycz, 1983; Buckley, 1985; Boender et al., 1989). The steps of Chang's extent analysis methods are as follows: Let $X=\left\{x_{1}, x_{2}, \ldots, x_{n}\right\}$ be an object set, and $U=\left\{u_{1}, u_{2}, \ldots, u_{m}\right\}$ be a goal set. According to the method of Chang's extent analysis, each object is taken and extent analysis for each goal, $g_{i}$, is performed, respectively. Therefore, $m$ extent analysis values for each object can be obtained, with the following signs:

$M_{g i}^{1}, M_{g i}^{2}, \ldots, M_{g i}^{m}, i=1,2, \ldots, n$.

Where all the $M_{g i}^{j}(j=1,2, \ldots, m)$ are TFNs.

The steps of Chang's extent analysis can be given as in the following:

Step 1- the value of fuzzy synthetic extent with respect to ith object is defined as:

$S_{i}=\sum_{j=1}^{m} M_{g i}^{j} \otimes\left[\sum_{i=1}^{n} \sum_{j=1}^{m} M_{g i}^{j}\right]^{-1}$

To obtain $\sum_{j=i}^{m} M_{g i}^{j}$, perform the fuzzy addition operation of $m$ extent analysis values for a particular matrix such that

$\sum_{j=1}^{m} M_{g i}^{j}=\left(\sum_{j=1}^{m} l_{i}, \sum_{j=1}^{m} m_{i}, \sum_{j=1}^{m} u_{i}\right)$

And to obtain $\left[\sum_{i=1}^{n} \sum_{j=1}^{m} M_{g i}^{j}\right]^{-1}$, perform the fuzzy addition operation of $M_{g i}^{j}(j=1,2, \ldots, m)$ values such that

$\sum_{i=1}^{n} \sum_{j=1}^{m} M_{g i}^{j}=\left(\sum_{i=1}^{n} l_{i}, \sum_{i=1}^{n} m_{i}, \sum_{i=1}^{n} u_{i}\right)$

And then compute the inverse of the vector in Eq. (10) such that

$\left[\sum_{n=1}^{n} \sum_{j=1}^{m} M_{g i}^{j}\right]^{-1}=\left(\frac{1}{\sum_{i=1}^{n} u_{i}}, \frac{1}{\sum_{i=1}^{n} m_{i}}, \frac{1}{\sum_{i=1}^{n} l_{i}}\right)$

Step 2- The degree of possibility of $M_{2}=\left(l_{2}, m_{2}, u_{2}\right) \geq M_{1}=\left(l_{1}, m_{1}, u_{1}\right)$ is defined as

$V\left(M_{2} \geq M_{1}\right)=\sup _{y \geq x}\left[\min \left(\mu_{M 1}(x), \mu_{M 2}(y)\right)\right]$

And can be equivalently expressed as follows:

$V\left(M_{2} \geq M_{1}\right)=h g t\left(M_{1} \cap M_{2}\right)=\mu_{M 2}(d)= \begin{cases}1, & \text { if } m_{2} \geq m_{1} \\ 0, & \text { if } l_{1} \geq u_{2} \\ \frac{l_{1}-u_{2}}{\left(m_{2}-u_{2}\right)-\left(m_{1}-l_{1}\right)}, & \text { otherwise }\end{cases}$

Where $d$ is the ordinate of highest intersection point $D$ between $\mu_{M 1}$ and $\mu_{M 2}$ (see Fig. 1).

To compare $M_{1}$ and $M_{2}$, we need both the values of $V\left(M_{1} \geq M_{2}\right)$ and $V\left(M_{2} \geq M_{1}\right)$.

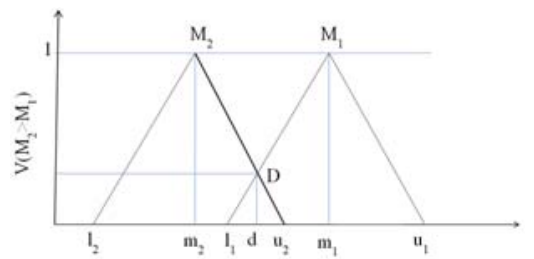

Fig. 1. The intersection between $M_{1}$ and $M_{2}$ (Chang, 1996) 
Step 3- The degree of possibility for a convex fuzzy number to be greater than $k$ convex fuzzy numbers $M_{i}(i=1,2, \ldots, k)$ can be defined by

$V\left(M \geq M_{1}, M_{2}, \ldots, M_{k}\right)=V\left[\left(M \geq M_{1}\right)\right.$ and $\left(M \geq M_{2}\right)$ and $\ldots$ and $\left.\left(M \geq M_{k}\right)\right]$

$=\min V\left(M \geq M_{i}\right), \quad \mathrm{i}=1,2, \ldots, \mathrm{k}$

Assume that

$d^{\prime}\left(A_{i}\right)=\min V\left(S_{i} \geq S_{k}\right)$

For $k=1,2, \ldots, n ; k \neq i$. Then the weight vector is given by

$W^{\prime}=\left(d^{\prime}\left(A_{1}\right), d^{\prime}\left(A_{2}\right), \ldots, d^{\prime}\left(A_{n}\right)\right)^{T}$

Where $A_{i}(i=1,2, \ldots, n)$ are $n$ elements.

Step 4- Via normalization, the normalized weight vectors are

$W=\left(d\left(A_{1}\right), d\left(A_{2}\right), \ldots, d\left(A_{n}\right)\right)^{T}$

where $W$ is a non-fuzzy number.

\section{FTOPSIS technique}

Technique for Order Preference by Similarity to Ideal Solution (TOPSIS) was developed by Hwang and Yoon (1981). This technique is an appropriate tool for selecting one or more alternatives from a pool of feasible alternatives with respect to the criteria under consideration. This method is based on the concept that the chosen alternative should have the shortest Euclidean distance from the ideal solution, and the farthest from the negative ideal solution. TOPSIS is combined with fuzzy, called FTOPSIS, because fuzzy allows the decision-makers to handle the incomplete information, nonobtainable information into decision model (Kulak et al., 2005). The FTOPSIS procedure can be defined as follows:

Step 1. Determine the weighting of the evaluation criteria. This research employs FAHP to find the relative weights of the criteria.

Step 2. Choose the linguistic rating for alternatives with respect to criteria. We deliberately select a 5point scale for defining the preference ratings of alternatives as given in Table 2 and Fig. 2.

Table 2

Linguistic terms for the preference rating of alternatives

\begin{tabular}{llllll}
\hline Linguistic term & Very poor (VP) & Poor (P) & Fair (F) & Good (G) & Very good (VG) \\
\hline Fuzzy number & $(0,1,3)$ & $(1,3,5)$ & $(3,5,7)$ & $(5,7,9)$ & $(7,9,10)$ \\
\hline
\end{tabular}

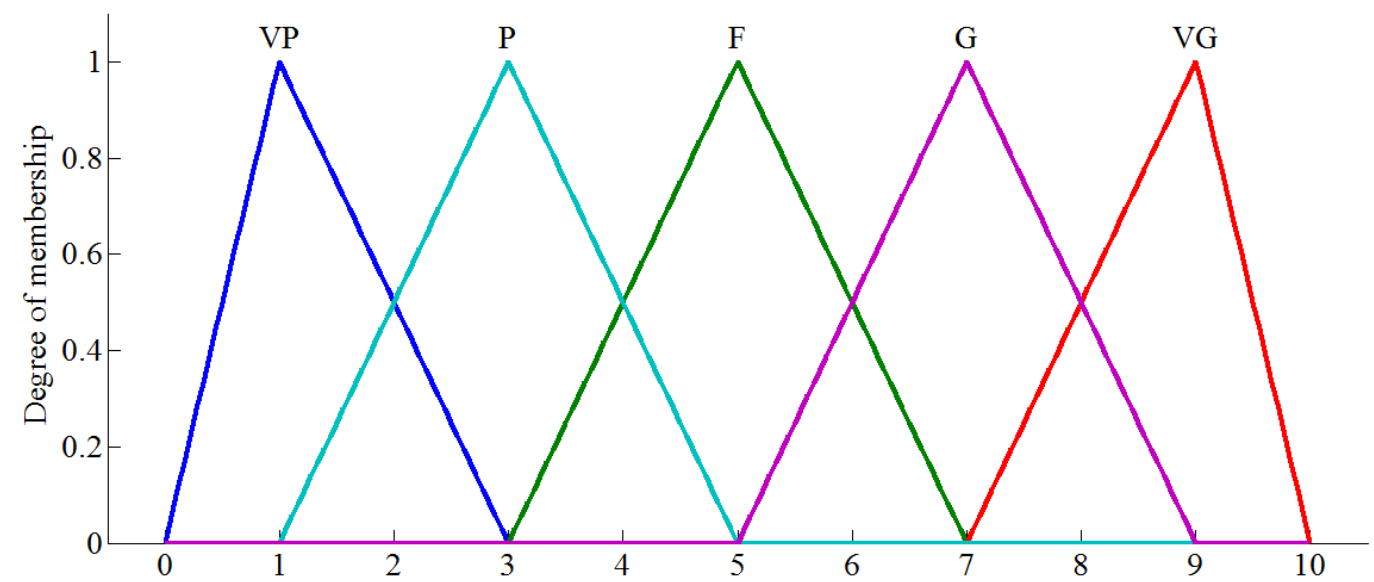

Fig. 2. Membership functions of linguistic values for preference rating 
Step 3. Construct the decision matrix, $\tilde{x}_{i j k}: i=1,2, \ldots, \mathrm{m} ; j=1,2, \ldots, \mathrm{n} ; k$ is the number of decision makers.

$$
\tilde{D}_{k}=\left[\begin{array}{cccc}
\tilde{x}_{11} & \mathrm{C}_{2} & \cdots & \mathrm{C}_{n} \\
\tilde{x}_{21}^{k} & \tilde{x}_{12}^{k} & \cdots & \tilde{x}_{1 n}^{k} \\
\vdots & \vdots & \ddots & \tilde{x}_{2 n}^{k} \\
\tilde{x}_{m 1}^{k} & \tilde{x}_{m 2}^{k} & & \tilde{x}_{m n}^{k}
\end{array}\right] A_{1}
$$

Step 4. Calculate aggregate fuzzy ratings for the evaluation criteria and the possible alternatives.

The weights and ratings given by different decision makers under different terms, the results of group decision making by using the arithmetic mean aggregation operator can integrate individual opinion.

$$
\begin{aligned}
& \tilde{D}=\left[\begin{array}{cccc}
\mathrm{C}_{1} & \mathrm{C}_{2} & \cdots & \mathrm{C}_{\mathrm{n}} \\
\tilde{x}_{11} & \tilde{x}_{12} & \cdots & \tilde{x}_{1 n} \\
\tilde{x}_{21} & \tilde{x}_{22} & \cdots & \tilde{x}_{2 n} \\
\vdots & \vdots & \ddots & \vdots \\
\tilde{x}_{m 1} & \tilde{x}_{m 2} & & \tilde{x}_{m n}
\end{array}\right] A_{1} \\
& W=\left[w_{1}, w_{2}, \ldots, w_{\mathrm{n}}\right]
\end{aligned}
$$

Where $\tilde{x}_{i j}$ is the aggregated fuzzy rating of alternative $\mathrm{A}_{i}$ with respect to criterion $\mathrm{C}_{j}$ evaluated by all experts and $w_{j}$ represents the weight of the $j$ th criterion.

$$
\begin{aligned}
& \tilde{x}_{\mathrm{ij}}=\left(\tilde{x}_{\mathrm{ij} 1}, \tilde{x}_{\mathrm{ij} 2}, \tilde{x}_{\mathrm{ij} 3}\right) \\
& \tilde{x}_{\mathrm{ij} 1}=\min \left\{\tilde{x}_{\mathrm{ij} 1}^{\mathrm{k}}\right\}, \tilde{\mathrm{x}}_{\mathrm{ij} 2}=\frac{1}{k} \sum_{k=1}^{k} \tilde{x}_{\mathrm{ij} 2}^{\mathrm{k}}, \tilde{x}_{i j 3}=\max \left\{\tilde{x}_{\mathrm{ij} 3}^{\mathrm{k}}\right\}
\end{aligned}
$$

Step 5. Construct the normalized fuzzy decision matrix. The normalized fuzzy decision matrix denoted by $\tilde{R}$ is shown as Eq. (21).

$$
\tilde{R}=\left[\tilde{r}_{\mathrm{ij}}\right]_{\mathrm{m} \times \mathrm{n}}
$$

Step 6. Construct the weighted normalized fuzzy decision matrix. The weighted normalized value $\tilde{V}$ is calculated by Eq. (22).

$$
\tilde{V}=\left[\begin{array}{cccc}
\tilde{v}_{11} & \tilde{v}_{12} & \cdots & \tilde{v}_{1 n} \\
\tilde{v}_{21} & \tilde{v}_{22} & \cdots & \tilde{v}_{2 n} \\
\vdots & \vdots & \ddots & \vdots \\
\tilde{v}_{m 1} & \tilde{v}_{m 2} & & \tilde{v}_{m n}
\end{array}\right]=\left[\begin{array}{cccc}
w_{1} \tilde{r}_{11} & w_{2} \tilde{r}_{12} & \cdots & w_{n} \tilde{r}_{1 n} \\
w_{1} \tilde{r}_{21} & w_{2} \tilde{r}_{22} & \cdots & w_{n} \tilde{r}_{2 n} \\
\vdots & \vdots & \ddots & \vdots \\
w_{1} \tilde{r}_{m 1} & w_{2} \tilde{r}_{m 2} & & w_{n} \tilde{r}_{m n}
\end{array}\right]
$$

Step 7. Identify positive ideal $\left(\mathrm{A}^{*}\right)$ and negative ideal $\left(\mathrm{A}^{-}\right)$solutions. The fuzzy positive -ideal solution and the fuzzy negative-ideal solution are shown in Eqs. (23), (24).

$$
\begin{aligned}
& A^{*}=\left(\tilde{v}_{1}^{+}, \tilde{v}_{2}^{+}, \tilde{v}_{3}^{+}, \ldots, \tilde{v}_{n}^{+}\right)=\left\{\max _{i} v_{i j} \mid(i=1,2, \ldots, n)\right\} \\
& A^{-}=\left(\tilde{v}_{1}^{-}, \tilde{v}_{2}^{-}, \tilde{v}_{3}^{-}, \ldots, \tilde{v}_{n}^{-}\right)=\left\{\min _{i} v_{i j} \mid(i=1,2, \ldots, n)\right\}
\end{aligned}
$$

According to the weighted normalized fuzzy-decision matrix, we know that the elements $\tilde{v}_{i j}$ are normalized positive TFN and their ranges is between zero and one. Thus, we can define the fuzzy 
positive-ideal solution and the negative-ideal as $\tilde{v}_{j}^{*}=w_{j} \otimes(1,1,1)$ and $\tilde{v}_{j}^{-}=(0,0,0)$, $j=1,2,3, \ldots, n$.

Step 8. Calculate separation measures. The distance of each alternative from $A^{*}$ and $A^{-}$can be currently calculated using Eqs. (25), (26).

$$
\begin{aligned}
& d_{i}^{+}=\sum_{j=1}^{n} d\left(\tilde{v}_{i j}, \tilde{v}_{j}^{+}\right), i=1,2, \ldots, m \\
& d_{i}^{-}=\sum_{j=1}^{n} d\left(\tilde{v}_{i j}, \tilde{v}_{j}^{-}\right), i=1,2, \ldots, m
\end{aligned}
$$

Step 9. Calculate the similarities to ideal solution. This step solves the similarities to an ideal solution by Eq. (27).

$$
C C_{i}^{*}=\frac{d_{i}^{-}}{d_{i}^{-}+d_{i}^{*}}
$$

Step 10. Rank each $C C_{i}^{*}$ of each alternative in descending order. The alternative with the top $C C_{i}^{*}$ value will be selected as the first choice.

\section{The proposed model}

The proposed model contains of three following steps:

1. Identify and determine the effective criteria and construct the hierarchical structure of the problem

2. Calculate the criteria weights by FAHP based on pairwise comparison matrices.

3. Rank alternatives in descending order and select the most appropriate alternative using FTOPSIS.

In the first step, alternatives and criteria are determined and the structure of hierarchy is constructed. In the second step, the relative weights of the criteria are evaluated by experts from mine design with high degree of knowledge in the field based on two-by-two comparisons. In this step, pairwise comparison matrixes are formed by decision makers based on the scale given in Table 1 . The values obtained from individual evaluations are converted into the aggregated pairwise comparison matrix to find a consensus on weight of the evaluation criteria.

In the third step, alternatives are ranked in descending order using FTOPSIS method and the alternative with the highest score is the best choice. Decision makers with the help of scale presented in Table 2 and Fig. 2, determine the rating of alternatives with respect to criterion under consideration, in the first phase of this step. After constructing the individual decision making matrices, these matrices are combined for obtaining the aggregated fuzzy ratings. Then, the computations of the FTOPSIS method for evaluating the existing alternatives with respect to the evaluation criteria based on the aggregated fuzzy ratings are implemented. In the last phase of this step, alternatives are prioritized according to the $C C_{i}$ values in descending order and the alternative with the top score is selected as the optimal handling equipment. Schematic diagram of the proposed model for handling equipment selection is shown in Fig. 3.

\section{An empirical application}

The purpose of the empirical application is to illustrate the use of the proposed method. The Sangan mine is one of the largest iron deposits of Iran which is situated $308 \mathrm{~km}$ southeast of Mashhad city in the north-east of the country (Fig. 4). This mine is designed to have an initial annual production of 3.4 Mt iron ore concentrate (Monjezi et al., 2011). 


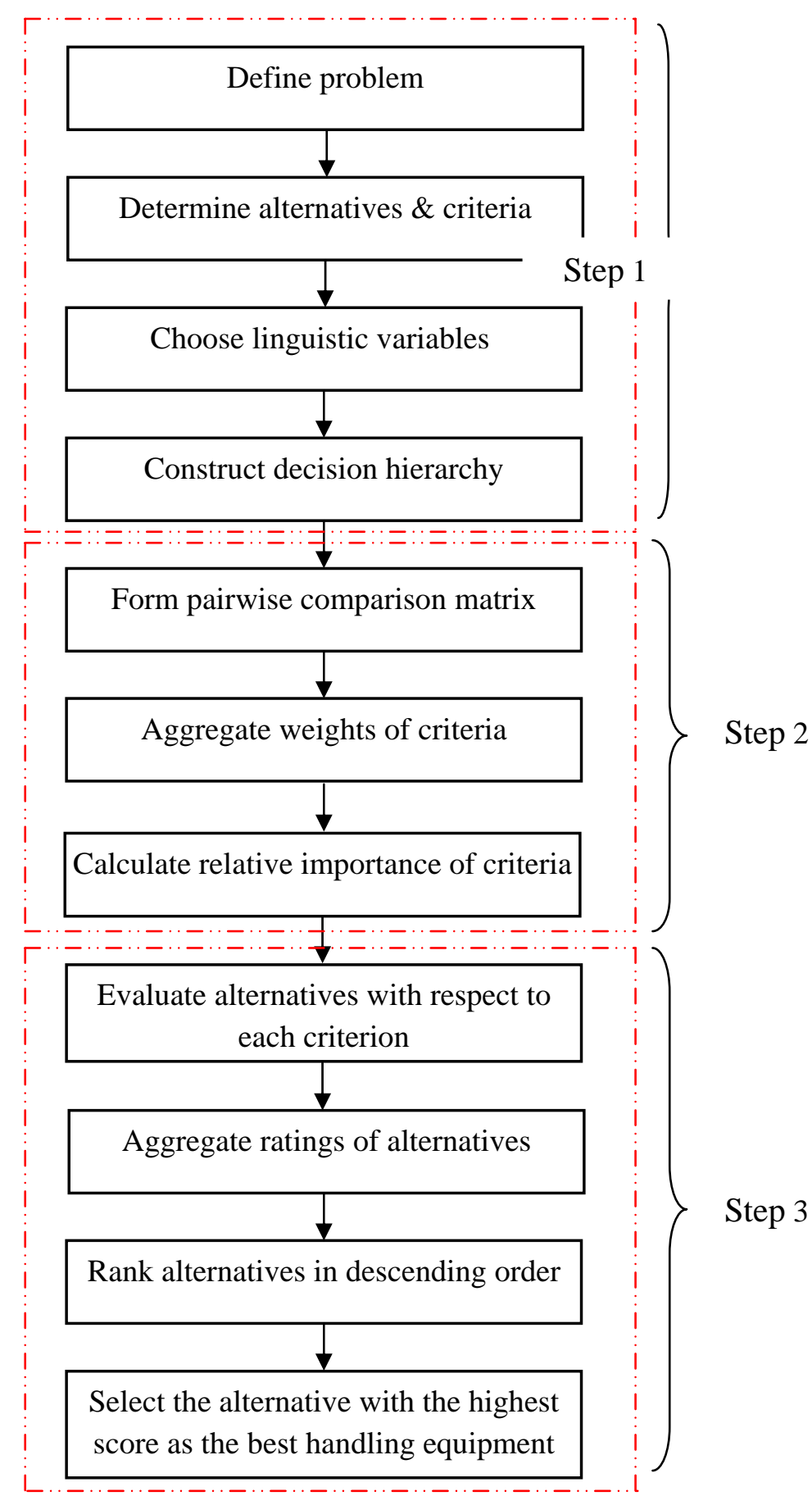

Fig. 3. Schematic diagram of the proposed model

The deposit of this mine comprises of a magnetite skarn and it is known as iron-oxide-type deposit. The case is implemented by using a step-by-step procedure as follows:

\section{Step 1. Identify and determine the effective criteria}

In the first step, the evaluation criteria in the decision making process should be determined. The evaluation criteria are identified from literature review and a lot of face-to-face interviews. After preliminary screening, the final list comprises of fifteen criteria to evaluate three alternatives belt conveyor system (A1), truck (A2), and truck-in-pit crusher-belt conveyor system (A3). These fifteen criteria are grouped into three main criteria, including Economic parameters (C1), Operating parameters 
(C2), and Technical parameters (C3). The first group contains of two sub-criteria Capital cost (C11) and Operation cost (C12). The second group comprises of seven sub-criteria Volume of resource (C21), Material size (C22), Ground condition (C23), Distance (C24), Weather condition (C25), Environment (C26), and Risk (C27). The last group includes six sub-criteria Reliability (C31), Efficiency (C32), Availability (C33), Safety (C34), Flexibility (C35), and Useful life (C36).

Out of fifteen criteria, three ones (i.e. C11, C12, and C27) are the cost category criteria (the lower, the better). The remaining criteria (i.e. C21, C22, C23, C24, C25, C26, C31, C32, C33, C34, C35, and C36) are the benefit type criteria (the higher, the better).

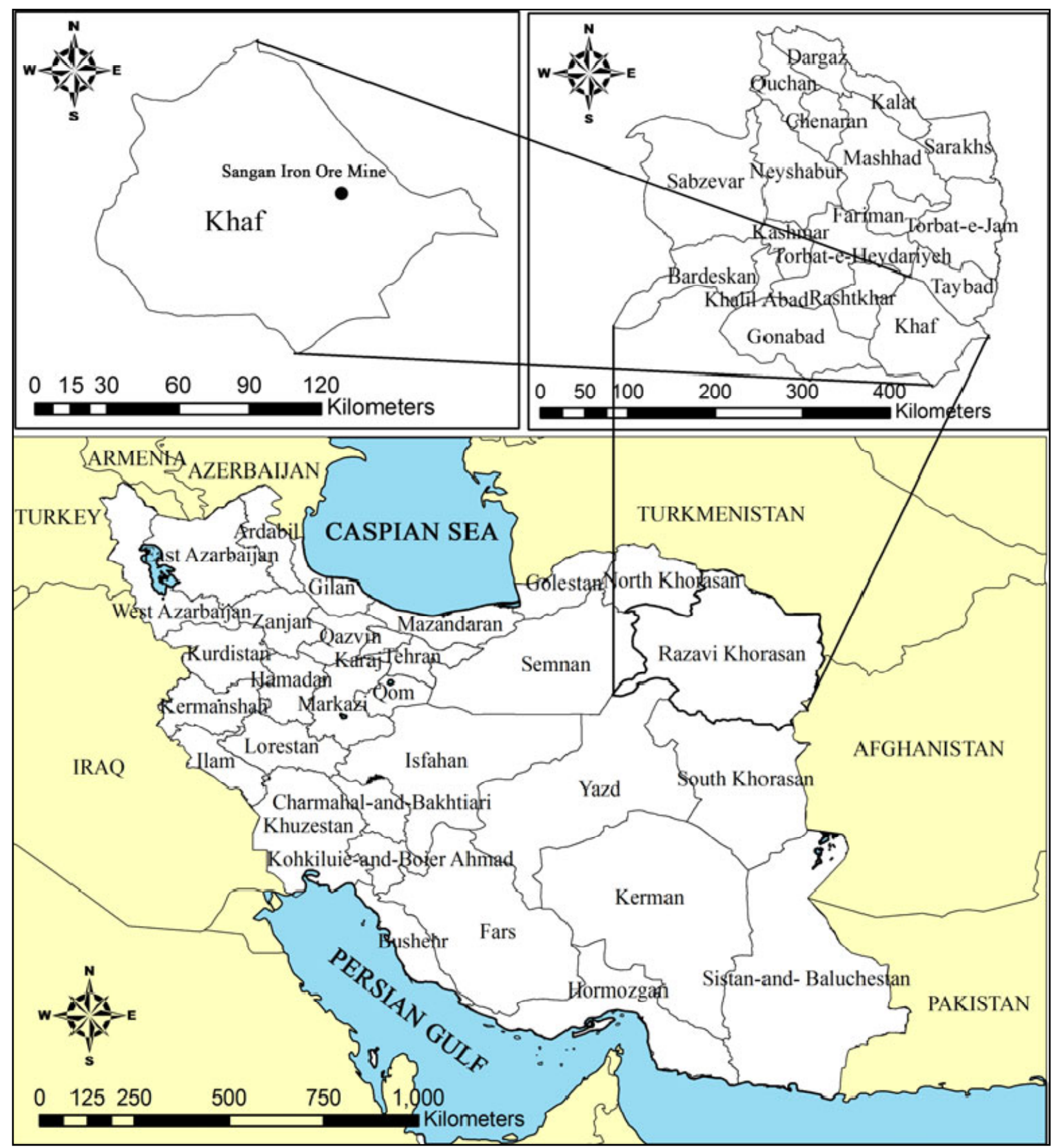

Fig. 4. Geography of Sangan iron mine (Naghizadeh et al., 2011) 
The structure of the decision hierarchy consists of four levels (see Fig. 5): the main objective of the problem is situated at the highest level, while in the second level, the criteria are presented, and in the third level, the sub-criteria are listed; the last level belongs to the alternatives.

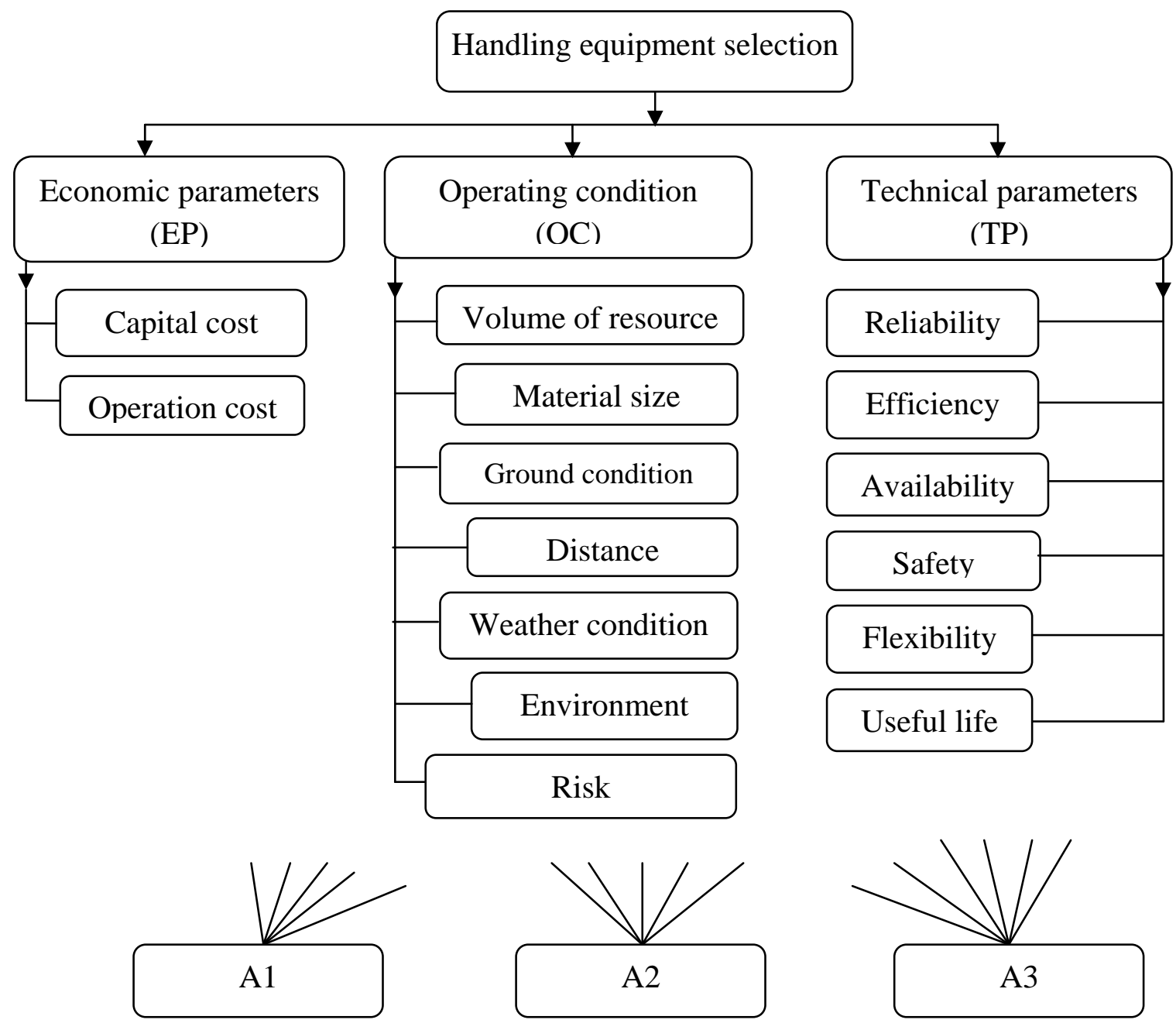

Fig. 5. Decision hierarchy

\section{Step 2. Calculate the criteria weights by FAHP}

After constructing the decision hierarchy, the FAHP method is applied for evaluating the relative importance of the evaluation criteria based on pairwise comparisons. For achieving the aim, ten decision makers construct individual pairwise comparison matrix based on the scale given in Table 1 . For example, when comparing the Capital cost and operation cost, the responses of ten experts are (W) ${ }^{1}$, E, (W), W, (W), E, W, E, E, and W, respectively.

The responses collected from ten questionnaires filled by the evaluators are converted into an aggregated pairwise comparison matrix by Eq. (28):

$\tilde{w}_{i j}=\left(\tilde{w}_{i j 1}, \tilde{w}_{i j 2}, \tilde{w}_{i j 3}\right)$

$\tilde{w}_{\mathrm{ij} 1}=\min \left\{\tilde{w}_{\mathrm{ij} 1}^{\mathrm{k}}\right\}, \tilde{w}_{\mathrm{ij} 2}=\frac{1}{k} \sum_{k=1}^{k} \tilde{w}_{\mathrm{ij} 2}^{\mathrm{k}}, \tilde{w}_{i j 3}=\max \left\{\tilde{w}_{\mathrm{ij} 3}^{\mathrm{k}}\right\}$

\footnotetext{
${ }^{1}$ Triangular fuzzy reciprocal scale
} 
Where $\tilde{w}_{i j}$ is the aggregated fuzzy weight of the $i$ th criterion in comparison with the $j$ th criterion evaluated by all decision makers. The results of the aggregated fuzzy weights are presented in Table 3.

Table 3

Aggregated fuzzy weights

\begin{tabular}{llllllllll}
\hline & & C1 & & & C2 & \multicolumn{3}{c}{ C3 } \\
\hline C1 & 1.00 & 1.00 & 1 & 0.33 & 1.21 & 3 & 1 & 2.23 & 4 \\
C2 & 0.33 & 0.83 & 3 & 1.00 & 1.00 & 1 & 1 & 2.12 & 3 \\
C3 & 0.25 & 0.45 & 1 & 0.33 & 0.47 & 1 & 1 & 1.00 & 1 \\
\hline
\end{tabular}

Table 3 Continued

\begin{tabular}{lllllll}
\hline & & C11 & & & C12 & \\
\hline C11 & 1.00 & 1.00 & 1 & 0.25 & 0.85 & 3 \\
C12 & 0.33 & 1.18 & 4 & 1.00 & 1.00 & 1 \\
\hline
\end{tabular}

Table 3 Continued

\begin{tabular}{lllllllllllllllllllllll}
\hline & C21 & & & C22 & & & C23 & & C24 & & C25 & & C26 & & & C27 \\
\hline C21 & 1 & 1 & 1 & 3.08 & 5 & 1 & 2.23 & 4 & 0.33 & 0.98 & 3 & 2 & 4.17 & 7 & 1 & 3.24 & 6.0 & 1 & 2.12 & 4 \\
$\mathrm{C} 220.2$ & 0.32 & 1 & 1 & 1.00 & 1 & 0.25 & 0.63 & 1 & 0.14 & 0.32 & 1 & 1 & 1.86 & 4 & 0.33 & 1.21 & 3.0 & 0.25 & 0.52 & 1 \\
$\mathrm{C} 230.25$ & 0.45 & 1 & 1 & 1.59 & 4 & 1 & 1.00 & 1 & 0.2 & 0.57 & 1 & 1 & 3.21 & 5 & 1 & 1.78 & 4.0 & 0.33 & 1.34 & 3 \\
$\mathrm{C} 240.33$ & 1.02 & 3 & 1 & 3.13 & 7 & 1 & 1.75 & 5 & 1 & 1.00 & 1 & 2 & 4.67 & 7 & 2 & 4.12 & 7.0 & 1 & 2.31 & 5 \\
$\mathrm{C} 250.14$ & 0.24 & 0.5 & 0.25 & 0.54 & 1 & 0.2 & 0.31 & 1 & 0.14 & 0.21 & 0.5 & 1 & 1.00 & 1 & 0.2 & 0.52 & 1.0 & 0.17 & 0.27 & 1 \\
$\mathrm{C} 260.17$ & 0.31 & 1 & 0.33 & 0.83 & 3 & 0.25 & 0.56 & 1 & 0.14 & 0.24 & 0.5 & 1 & 1.92 & 5 & 1 & 1.00 & 1.0 & 0.2 & 0.46 & 1 \\
$\mathrm{C} 270.25$ & 0.47 & 1 & 1 & 1.92 & 4 & 0.33 & 0.75 & 3 & 0.2 & 0.43 & 1 & 1 & 1.70 & 6 & 1 & 2.17 & 5.0 & 1 & 1.00 & 1 \\
\hline
\end{tabular}

Table 3 Continued

\begin{tabular}{lllllllllllllllllll}
\hline & C31 & & & C32 & & C33 & & C34 & & C35 & & C36 \\
\hline C31 & 1 & 1.00 & 1 & 0.33 & 1.09 & 3 & 1 & 2.45 & 4 & 0.33 & 0.98 & 3 & 3 & 4.87 & 8 & 2 & 3.12 & 5 \\
C32 & 0.33 & 0.92 & 3 & 1 & 1.00 & 1 & 1 & 2.27 & 5 & 0.33 & 1.12 & 4 & 2 & 4.12 & 6 & 1 & 2.21 & 4 \\
C33 & 0.25 & 0.41 & 1 & 0.2 & 0.44 & 1 & 1 & 1.00 & 1 & 0.2 & 0.57 & 1 & 1 & 2.42 & 4 & 0.33 & 1.07 & 3 \\
C34 & 0.33 & 1.02 & 3 & 0.25 & 0.89 & 3 & 1 & 1.75 & 5 & 1 & 1.00 & 1 & 2 & 3.97 & 6 & 2 & 3.36 & 5 \\
C35 & 0.13 & 0.21 & 0.33 & 0.17 & 0.24 & 0.5 & 0.25 & 0.41 & 1 & 0.17 & 0.25 & 0.5 & 1 & 1.00 & 1 & 0.17 & 0.39 & 1 \\
C36 & 0.2 & 0.32 & 0.50 & 0.25 & 0.45 & 1 & 0.33 & 0.93 & 3 & 0.2 & 0.30 & 0.5 & 1 & 2.56 & 6 & 1 & 1 & 1 \\
\hline
\end{tabular}

In this paper, Chang's FAHP methodology is used for calculating the elements of the synthetic pairwise comparison matrix in order to obtain the relative importance of the criteria. Therefore, from Table 3, synthesis values respect to main goal are calculated as follows:

$$
\begin{aligned}
& S_{C 1}=(0.056,0.097,0.16) \otimes(2.33,4.44,8.0)=(0.13,0.43,1.28) \\
& S_{C 2}=(0.056,0.097,0.16) \otimes(2.33,3.95,7.0)=(0.13,0.38,1.12) \\
& S_{C 3}=(0.056,0.097,0.16) \otimes(1.58,1.92,3.0)=(0.09,0.19,0.48) \\
& S_{C 11}=(0.111,0.248,0.387) \otimes(1.25,1.85,4.0)=(0.14,0.46,1.55) \\
& S_{C 12}=(0.111,0.248,0.387) \otimes(1.33,2.18,5.0)=(2.12,2.73,3.63) \\
& S_{C 21}=(0.007,0.014,0.03) \otimes(7.33,16.82,30.0)=(0.054,0.242,0.893) \\
& S_{C 22}=(0.007,0.014,0.03) \otimes(3.18,5.86,12.0)=(0.023,0.084,0.357) \\
& S_{C 23}=(0.007,0.014,0.03) \otimes(4.48,9.94,19.0)=(0.035,0.143,0.565) \\
& S_{C 24}=(0.007,0.014,0.03) \otimes(8.33,18.0,35.0)=(0.062,0.259,1.042) \\
& S_{C 25}=(0.007,0.014,0.03) \otimes(2.1,3.09,6.0)=(0.016,0.045,0.179)
\end{aligned}
$$


$S_{C 26}=(0.007,0.014,0.03) \otimes(3.09,5.32,12.5)=(0.023,0.077,0.372)$

$S_{C 27}=(0.007,0.014,0.03) \otimes(4.78,10.45,21.0)=(0.035,0.15,0.625)$

$S_{C 31}=(0.01,0.02,0.036) \otimes(7.67,13.51,24.0)=(0.08,0.26,0.86)$

$S_{C 32}=(0.01,0.02,0.036) \otimes(5.67,11.64,23.0)=(0.06,0.23,0.83)$

$S_{C 33}=(0.01,0.02,0.036) \otimes(2.98,5.91,11.0)=(0.03,0.12,0.4)$

$S_{C 34}=(0.01,0.02,0.036) \otimes(6.58,12.0,23.0)=(0.07,0.23,0.83)$

$S_{C 35}=(0.01,0.02,0.036) \otimes(1.88,2.5,4.33)=(0.02,0.05,0.16)$

$S_{C 36}=(0.01,0.02,0.036) \otimes(2.98,5.57,12.0)=(0.03,0.11,0.43)$

Then the $V$ values calculated using these vectors are presented in Table 4 .

Table 4

$V$ values result

\begin{tabular}{lllllll}
\hline & $S_{C 1}$ & $S_{C 2}$ & $S_{C 3}$ & & $S_{C 11}$ & $S_{C 12}$ \\
\hline$V\left(S_{C 1} \geq \cdots\right)$ & & 1 & 1 & $V\left(S_{C 11} \geq \cdots\right)$ & & 0.95 \\
$V\left(S_{C 2} \geq \cdots\right)$ & 0.95 & & 1 & $V\left(S_{C 12} \geq \cdots\right)$ & 1 & \\
$V\left(S_{C 3} \geq \cdots\right)$ & 0.59 & 0.64 & & & & \\
\hline
\end{tabular}

Table 4 Continued

\begin{tabular}{llllllll}
\hline & $S_{C 21}$ & $S_{C 22}$ & $S_{C 23}$ & $S_{C 24}$ & $S_{C 25}$ & $S_{C 26}$ & $S_{C 27}$ \\
\hline$V\left(S_{C 21} \geq \cdots\right)$ & & 1 & 1 & 0.98 & 1 & 1 & 1 \\
$V\left(S_{C 22} \geq \cdots\right)$ & 0.66 & & 0.85 & 0.63 & 1 & 1 & 0.83 \\
$V\left(S_{C 23} \geq \cdots\right)$ & 0.84 & 1 & & 0.81 & 1 & 1 & 0.99 \\
$V\left(S_{C 24} \geq \cdots\right)$ & 1 & 1 & 1 & & 1 & 1 & 1 \\
$V\left(S_{C 25} \geq \cdots\right)$ & 1 & 0.8 & 0.59 & 0.35 & & 0.83 & 0.57 \\
$V\left(S_{C 26} \geq \cdots\right)$ & 0.66 & 0.98 & 0.84 & 0.63 & 1 & & 0.82 \\
$V\left(S_{C 27} \geq \cdots\right)$ & 0.86 & 1 & 1 & 0.84 & 1 & 1 & \\
\hline
\end{tabular}

Table 4 Continued

\begin{tabular}{lllllll}
\hline & $S_{C 31}$ & $S_{C 32}$ & $S_{C 33}$ & $S_{C 34}$ & $S_{C 35}$ & $S_{C 36}$ \\
\hline$V\left(S_{C 31} \geq \cdots\right)$ & & 1 & 1 & 1 & 1 & 1 \\
$V\left(S_{C 32} \geq \cdots\right)$ & 0.95 & & 1 & 0.99 & 1 & 1 \\
$V\left(S_{C 33} \geq \cdots\right)$ & 0.68 & 0.75 & & 0.73 & 1 & 1 \\
$V\left(S_{C 34} \geq \cdots\right)$ & 0.96 & 1 & 1 & & 1 & 1 \\
$V\left(S_{C 35} \geq \cdots\right)$ & 1 & 0.35 & 0.65 & 0.32 & & 0.68 \\
$V\left(S_{C 36} \geq \cdots\right)$ & 0.69 & 0.76 & 0.98 & 0.74 & 1 & \\
\hline
\end{tabular}

Then priority weights of criteria are calculated through Eq. (15):

$d^{\prime}(C 1)=\min (1,1)=1$

$d^{\prime}(C 2)=\min (0.95,1)=0.95$

$d^{\prime}(C 3)=\min (0.59,0.64)=0.59$

$d^{\prime}(C 11)=0.95$ 
$d^{\prime}(C 12)=1$

$d^{\prime}(C 21)=\min (1,1,0.98,1,1,1)=0.98$

$d^{\prime}(C 22)=\min (0.66,0.85,0.63,1,1,0.83)=0.63$

$d^{\prime}(C 23)=\min (0.84,1,0.81,1,1,0.99)=0.81$

$d^{\prime}(C 24)=\min (1,1,1,1,1,1)=1$

$d^{\prime}(C 25)=\min (1,0.8,0.59,0.35,0.83,0.57)=0.35$

$d^{\prime}(C 26)=\min (0.66,0.98,0.84,0.63,1,0.82)=0.63$

$d^{\prime}(C 27)=\min (0.86,1,1,0.84,1,1)=0.84$

$d^{\prime}(C 31)=\min (1,1,1,1,1)=1$

$d^{\prime}(C 32)=\min (0.95,1,0.99,1,1)=0.95$

$d^{\prime}(C 33)=\min (0.68,0.75,0.73,1,1)=0.68$

$d^{\prime}(C 34)=\min (0.96,1,1,1,1)=0.96$

$d^{\prime}(C 35)=\min (1,0.35,0.65,0.32,0.68)=0.32$

$d^{\prime}(C 36)=\min (0.69,0.76,0.98,0.74,1)=0.69$

Local weights of sub-criteria form $W^{\prime}=(0.95,1,0.98,0.63,0.81,1,0.35,0.63,0.84,1,0.95,0.68,0.96,0.32,0.69)$ vector. After multiplying the local weights of sub-criteria by the local weights of main-criteria and the normalization of these values, priority weights respect to main objective are resulted as $(0.196,0.207$, 0.069, 0.044, 0.057, 0.07, 0.025, 0.044, 0.059, 0.049, 0.047, 0.034, 0.047, 0.016, 0.034). Mentioned priority weights have shown for each criterion in Table 5. The FAHP analysis of the criteria is summarized in Fig. 6.

\section{Table 5}

Priority weights for each criterion

\begin{tabular}{lcclcc}
\hline Main and sub-criteria & Local weights & Global weights & Main and sub-criteria & Local weights & Global weights \\
\hline Economic parameters & 0.403 & - & Environment & 0.120 & 0.044 \\
\hline Capital cost & 0.486 & 0.196 & Risk & 0.160 & 0.059 \\
\hline Operation cost & 0.514 & 0.207 & Technical parameters & 0.228 & - \\
\hline Operating parameters & 0.369 & - & Reliability & 0.217 & 0.049 \\
\hline Volume of resource & 0.187 & 0.069 & Efficiency & 0.207 & 0.047 \\
\hline Material size & 0.120 & 0.044 & Availability & 0.148 & 0.034 \\
\hline Ground condition & 0.155 & 0.057 & Safety & 0.209 & 0.047 \\
\hline Distance & 0.191 & 0.070 & Flexibility & 0.070 & 0.016 \\
\hline Weather condition & 0.067 & 0.025 & Useful life & 0.151 & 0.034 \\
\hline
\end{tabular}

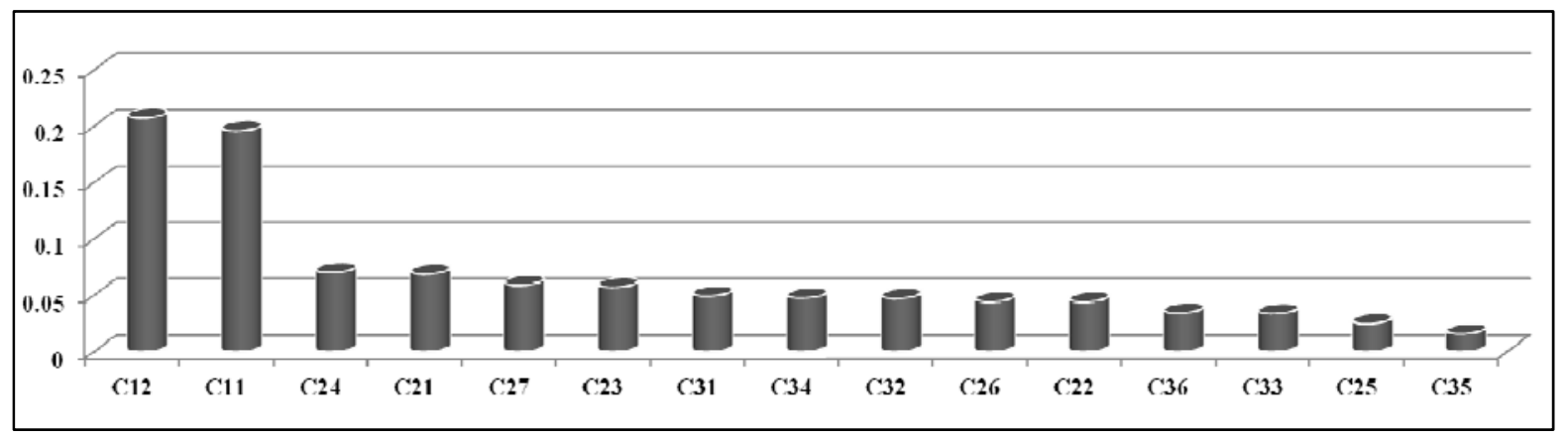

Fig. 6. Ranking of criteria

\section{Step 3. Select the most appropriate handling equipment using FTOPSIS}

In this step, alternatives with respect to criteria were evaluated by ten decision makers. These decision makers expressed the level of performance for each alternative whit respect to criteria in linguistic 
variables according to the linguistic scales and corresponding numbers given in Table 2 and Fig. 2. The individual fuzzy decision matrix is formed by decision maker team. For example, the responses of one of the experts for preference ratings of the alternatives are listed in Table 6.

\section{Table 6}

A sample of filled questionnaire

\begin{tabular}{|c|c|c|c|c|c|c|c|}
\hline & A1 & $\mathrm{A} 2$ & A3 & & A1 & A2 & A3 \\
\hline$\overline{\mathrm{C} 11}$ & $\mathrm{G}$ & $\mathrm{P}$ & $\mathrm{VG}$ & C27 & VG & $\mathrm{P}$ & $\mathrm{G}$ \\
\hline C12 & $\mathrm{P}$ & $\mathrm{F}$ & VP & C31 & F & $\mathrm{G}$ & $\mathrm{G}$ \\
\hline C21 & VG & $\mathrm{G}$ & VG & C32 & $\mathrm{G}$ & $\mathrm{F}$ & VG \\
\hline C22 & VP & VG & $\mathrm{G}$ & C33 & $\mathrm{G}$ & VG & $\mathrm{P}$ \\
\hline C23 & VP & $\mathrm{G}$ & $\mathrm{G}$ & C34 & $\mathrm{G}$ & F & $\mathrm{F}$ \\
\hline C24 & $\mathrm{G}$ & $\mathrm{G}$ & VG & C35 & VP & VG & $\mathrm{F}$ \\
\hline C25 & VP & $\mathrm{G}$ & $\mathrm{P}$ & C36 & VG & $\mathrm{F}$ & $\mathrm{G}$ \\
\hline
\end{tabular}

Then, the aggregated fuzzy performance ratings of handling equipment with respect to each criterion are calculated via Eq. (20) as presented in Table 7.

Table 7

Aggregated fuzzy performance ratings

\begin{tabular}{llllllllll}
\hline & A1 & \multicolumn{3}{c}{ A2 } & \multicolumn{5}{c}{ A3 } \\
\hline C11 & 3 & 6.37 & 9 & 1 & 3.17 & 7 & 5 & 7.65 & 10 \\
C12 & 1 & 3.21 & 7 & 1 & 3.87 & 7 & 1 & 3.09 & 7 \\
C21 & 5 & 7.43 & 10 & 3 & 6.53 & 9 & 5 & 7.23 & 10 \\
C22 & 0 & 2.07 & 5 & 5 & 7.76 & 10 & 3 & 6.42 & 9 \\
C23 & 0 & 2.12 & 5 & 3 & 6.59 & 9 & 3 & 6.89 & 10 \\
C24 & 3 & 6.24 & 9 & 3 & 6.74 & 10 & 5 & 7.32 & 10 \\
C25 & 0 & 1.87 & 5 & 3 & 6.34 & 9 & 0 & 3.17 & 7 \\
C26 & 3 & 6.54 & 9 & 1 & 4.46 & 9 & 3 & 6.32 & 9 \\
C27 & 5 & 7.87 & 10 & 1 & 3.12 & 7 & 3 & 6.94 & 10 \\
C31 & 1 & 4.31 & 7 & 3 & 6.43 & 9 & 3 & 6.57 & 9 \\
C32 & 3 & 6.45 & 9 & 1 & 4.57 & 7 & 5 & 7.12 & 10 \\
C33 & 3 & 6.92 & 10 & 5 & 7.56 & 10 & 1 & 3.24 & 7 \\
C34 & 1 & 6.21 & 9 & 1 & 4.23 & 7 & 1 & 4.36 & 7 \\
C35 & 0 & 3.12 & 7 & 5 & 7.21 & 10 & 1 & 4.67 & 9 \\
C36 & 5 & 7.56 & 10 & 3 & 5.17 & 7 & 3 & 6.78 & 10 \\
\hline
\end{tabular}

According to the FTOPSIS computations, the aggregated fuzzy decision matrix needs to be normalized by using Eqs. (29) and (30):

$r_{i j}=\frac{x_{i j}-\min \left\{x_{i j}\right\}}{\left[\max \left\{x_{i j}\right\}-\min \left\{x_{i j}\right\}\right]} \quad$ The larger the better type

$r_{i j}=\frac{\min \left\{x_{i j}\right\}-x_{i j}}{\left[\max \left\{x_{i j}\right\}-\min \left\{x_{i j}\right\}\right]} \quad$ The smaller the better type

Then, the weighted fuzzy decision matrix for the alternatives is calculated by multiplying the weights of criteria, derived from FAHP, with the normalized fuzzy decision matrix obtained in previous phase as presented in Table 8. 
Table 8

Weighted fuzzy decision matrix

\begin{tabular}{|c|c|c|c|c|c|c|c|c|c|}
\hline & A1 & & & A2 & & & A3 & & \\
\hline$\overline{\mathrm{C} 11}$ & 0.022 & 0.079 & 0.152 & 0.065 & 0.149 & 0.196 & 0.000 & 0.051 & 0.109 \\
\hline C12 & 0.000 & 0.131 & 0.207 & 0.000 & 0.108 & 0.207 & 0.000 & 0.135 & 0.207 \\
\hline C21 & 0.020 & 0.044 & 0.069 & 0.000 & 0.035 & 0.059 & 0.020 & 0.042 & 0.069 \\
\hline C22 & 0.000 & 0.009 & 0.022 & 0.022 & 0.034 & 0.044 & 0.013 & 0.028 & 0.040 \\
\hline C23 & 0.000 & 0.012 & 0.029 & 0.017 & 0.038 & 0.051 & 0.017 & 0.039 & 0.057 \\
\hline C24 & 0.000 & 0.033 & 0.060 & 0.000 & 0.038 & 0.070 & 0.020 & 0.043 & 0.070 \\
\hline C25 & 0.000 & 0.005 & 0.014 & 0.008 & 0.017 & 0.025 & 0.000 & 0.009 & 0.019 \\
\hline C26 & 0.011 & 0.031 & 0.044 & 0.000 & 0.019 & 0.044 & 0.011 & 0.029 & 0.044 \\
\hline C27 & 0.000 & 0.014 & 0.033 & 0.020 & 0.045 & 0.059 & 0.000 & 0.020 & 0.046 \\
\hline C31 & 0.000 & 0.020 & 0.037 & 0.012 & 0.034 & 0.049 & 0.012 & 0.034 & 0.049 \\
\hline C32 & 0.010 & 0.028 & 0.042 & 0.000 & 0.019 & 0.031 & 0.021 & 0.032 & 0.047 \\
\hline C33 & 0.007 & 0.022 & 0.034 & 0.015 & 0.025 & 0.034 & 0.000 & 0.008 & 0.022 \\
\hline C34 & 0.000 & 0.031 & 0.047 & 0.000 & 0.019 & 0.036 & 0.000 & 0.020 & 0.036 \\
\hline C35 & 0.000 & 0.005 & 0.011 & 0.008 & 0.011 & 0.016 & 0.002 & 0.007 & 0.014 \\
\hline C36 & 0.010 & 0.022 & 0.034 & 0.000 & 0.011 & 0.020 & 0.000 & 0.019 & 0.034 \\
\hline
\end{tabular}

Then, the fuzzy positive ideal solution (FPIS, $A^{+}$) and the fuzzy negative ideal solutions (FNIS, $A^{-}$) can be defined as $\tilde{v}_{i}^{+}=w_{j} \otimes(1,1,1)$ and $\tilde{v}_{i}^{-}=(0,0,0)$. The distance of each risk from $A^{+}$and $A^{-}$with respect to each criterion are calculated with the help of Eqs. (23) and (24). By applying Eq. (27), the closeness Icoefficient is calculated as listed in Table 6.

In the last phase of this step, the feasible alternatives are ranked in descending order as presented in Table 9. According to $\mathrm{CC}_{\mathrm{i}}$ values, the final ranking of the alternatives in descending order are $\mathrm{A} 2, \mathrm{~A} 3$, and A1. The proposed model shows that Truck (A2) is the best handling equipment with CC value of 0.556. Final rankings of the handling equipment based on $\mathrm{CC}_{\mathrm{i}}$ values are depicted in Fig. 7.

\section{Table 9}

FTOPSIS results

\begin{tabular}{lllll}
\hline & $d_{i}^{+}$ & $d_{i}^{-}$ & $C C_{i}$ & Rank \\
\hline A1 & 0.615 & 0.564 & 0.478 & 3 \\
A2 & 0.529 & 0.661 & 0.556 & 1 \\
A3 & 0.588 & 0.592 & 0.502 & 2 \\
\hline
\end{tabular}

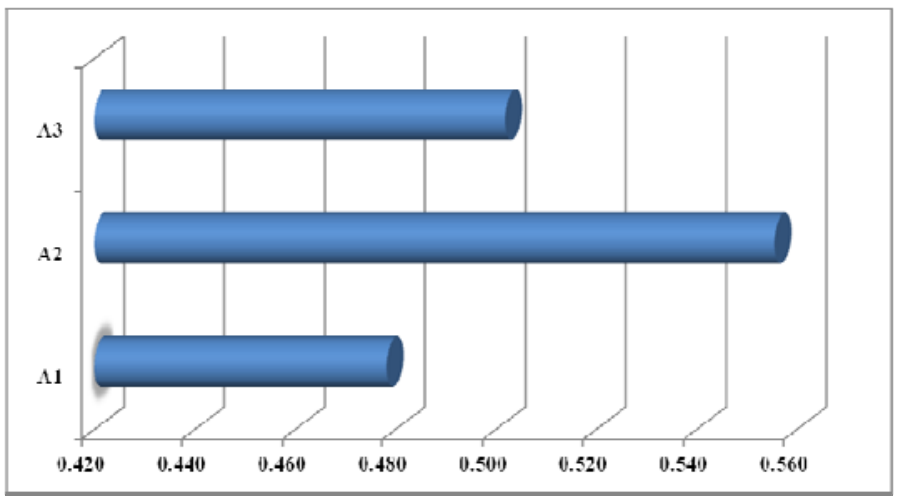

Fig. 7. Final ranking of alternatives

\section{Sensitivity analysis}

Sensitivity analysis is a powerful tool for evaluating the proposed model in order to calculate the stability of the results by changing the priorities of the evaluation criteria and reflect the strength of the constructed model. In this paper, the priorities for evaluation criteria are changed one at a time to 
perform sensitivity analysis, and the changes range is presented in Table 10. Fig. 8 depicts the sensitivity analysis graph when the priorities of the criteria are changed.

It can be shown from Table 10 and Fig. 8 that out of 30 experiments, alternative A2 has the highest score in thirty seven experiments. In two experiments 18 and 26, A3 is the winner and in the remaining one experiment (30), A1 is the winner. Therefore, it can be resulted that the decision making process is rarely sensitive to the criteria weight with alternative A2 emerging as the winner ( $90 \%$ votes).

\section{Table 10}

Changing the criteria weights for sensitivity analysis

\begin{tabular}{|c|c|c|c|c|c|}
\hline No. & Weights of criteria & Ranking & No. & Weights of criteria & Ranking \\
\hline 1 & $W_{C 11(\text { new })}=3 \times W_{C 11(\text { old })}$ & $\mathrm{A} 2>\mathrm{A} 3>\mathrm{A} 1$ & 16 & $W_{C 11(\text { new })}=10 \times W_{C 11(\text { old })}$ & $\mathrm{A} 2>\mathrm{A} 3>\mathrm{A} 1$ \\
\hline 2 & $W_{C 12(\text { new })}=3 \times W_{C 12(\text { old })}$ & $\mathrm{A} 2>\mathrm{A} 3>\mathrm{A} 1$ & 17 & $W_{C 12(\text { new })}=10 \times W_{C 12(\text { old })}$ & $\mathrm{A} 2>\mathrm{A} 3>\mathrm{A} 1$ \\
\hline 3 & $W_{C 21(\text { new })}=3 \times W_{C 21(\text { old })}$ & $\mathrm{A} 2>\mathrm{A} 3>\mathrm{A} 1$ & 18 & $W_{C 21(\text { new })}=10 \times W_{C 21 \text { (old })}$ & $\mathrm{A} 3>\mathrm{A} 1>\mathrm{A} 2$ \\
\hline 4 & $W_{C 22(\text { new })}=3 \times W_{C 22(\text { old })}$ & $\mathrm{A} 2>\mathrm{A} 3>\mathrm{A} 1$ & 19 & $W_{C 22(\text { new })}=10 \times W_{C 22(\text { old })}$ & $\mathrm{A} 2>\mathrm{A} 3>\mathrm{A} 1$ \\
\hline 5 & $W_{C 23(\text { new })}=3 \times W_{C 23(\text { old })}$ & $\mathrm{A} 2>\mathrm{A} 3>\mathrm{A} 1$ & 20 & $W_{C 23(\text { new })}=10 \times W_{C 23(\text { old })}$ & $\mathrm{A} 2>\mathrm{A} 3>\mathrm{A} 1$ \\
\hline 6 & $W_{C 24(\text { new })}=3 \times W_{C 24(\text { old })}$ & $\mathrm{A} 2>\mathrm{A} 3>\mathrm{A} 1$ & 21 & $W_{C 24(\text { new })}=10 \times W_{C 24(\text { old })}$ & $\mathrm{A} 2>\mathrm{A} 3>\mathrm{A} 1$ \\
\hline 7 & $W_{C 25(\text { new })}=3 \times W_{C 25(\text { old })}$ & $\mathrm{A} 2>\mathrm{A} 3>\mathrm{A} 1$ & 22 & $W_{C 25(\text { new })}=10 \times W_{C 25(\text { old })}$ & $\mathrm{A} 2>\mathrm{A} 3>\mathrm{A} 1$ \\
\hline 8 & $W_{C 26(\text { new })}=3 \times W_{C 26(\text { old })}$ & $\mathrm{A} 2>\mathrm{A} 3>\mathrm{A} 1$ & 23 & $W_{C 26(\text { new })}=10 \times W_{C 26(\text { old })}$ & $\mathrm{A} 2>\mathrm{A} 3>\mathrm{A} 1$ \\
\hline 9 & $W_{C 27 \text { (new) }}=3 \times W_{C 27 \text { (old) }}$ & $\mathrm{A} 2>\mathrm{A} 3>\mathrm{A} 1$ & 24 & $W_{C 27 \text { (new) }}=10 \times W_{C 27 \text { (old) }}$ & $\mathrm{A} 2>\mathrm{A} 3>\mathrm{A} 1$ \\
\hline 10 & $W_{C 31(\text { new })}=3 \times W_{C 31(\text { old })}$ & $\mathrm{A} 2>\mathrm{A} 3>\mathrm{A} 1$ & 25 & $W_{C 31(\text { new })}=10 \times W_{C 31(\text { old })}$ & $\mathrm{A} 2>\mathrm{A} 3>\mathrm{A} 1$ \\
\hline 11 & $W_{C 32(\text { new })}=3 \times W_{C 32(\text { old })}$ & $\mathrm{A} 2>\mathrm{A} 3>\mathrm{A} 1$ & 26 & $W_{C 32(\text { new })}=10 \times W_{C 32(\text { old })}$ & $\mathrm{A} 3>\mathrm{A} 2>\mathrm{A} 1$ \\
\hline 12 & $W_{C 33(\text { new })}=3 \times W_{C 33(\text { old })}$ & $\mathrm{A} 2>\mathrm{A} 3>\mathrm{A} 1$ & 27 & $W_{C 33(\text { new) }}=10 \times W_{\text {C33(old) }}$ & $\mathrm{A} 2>\mathrm{A} 3>\mathrm{A} 1$ \\
\hline 13 & $W_{C 34(\text { new) }}=3 \times W_{\text {C34(old) }}$ & $\mathrm{A} 2>\mathrm{A} 3>\mathrm{A} 1$ & 28 & $W_{C 34(\text { new })}=10 \times W_{C 34 \text { (old) }}$ & $\mathrm{A} 2>\mathrm{A} 3>\mathrm{A} 1$ \\
\hline 14 & $W_{C 35(\text { new })}=3 \times W_{C 35(\text { old })}$ & $\mathrm{A} 2>\mathrm{A} 3>\mathrm{A} 1$ & 29 & $W_{C 35(\text { new })}=10 \times W_{C 35(\text { old })}$ & $\mathrm{A} 2>\mathrm{A} 3>\mathrm{A} 1$ \\
\hline 15 & $W_{C 36 \text { (new) }}=3 \times W_{C 36(\text { old })}$ & $\mathrm{A} 2>\mathrm{A} 3>\mathrm{A} 1$ & 30 & $W_{C 36(\text { new })}=10 \times W_{C 36(\text { old })}$ & $\mathrm{A} 1>\mathrm{A} 2>\mathrm{A} 3$ \\
\hline
\end{tabular}

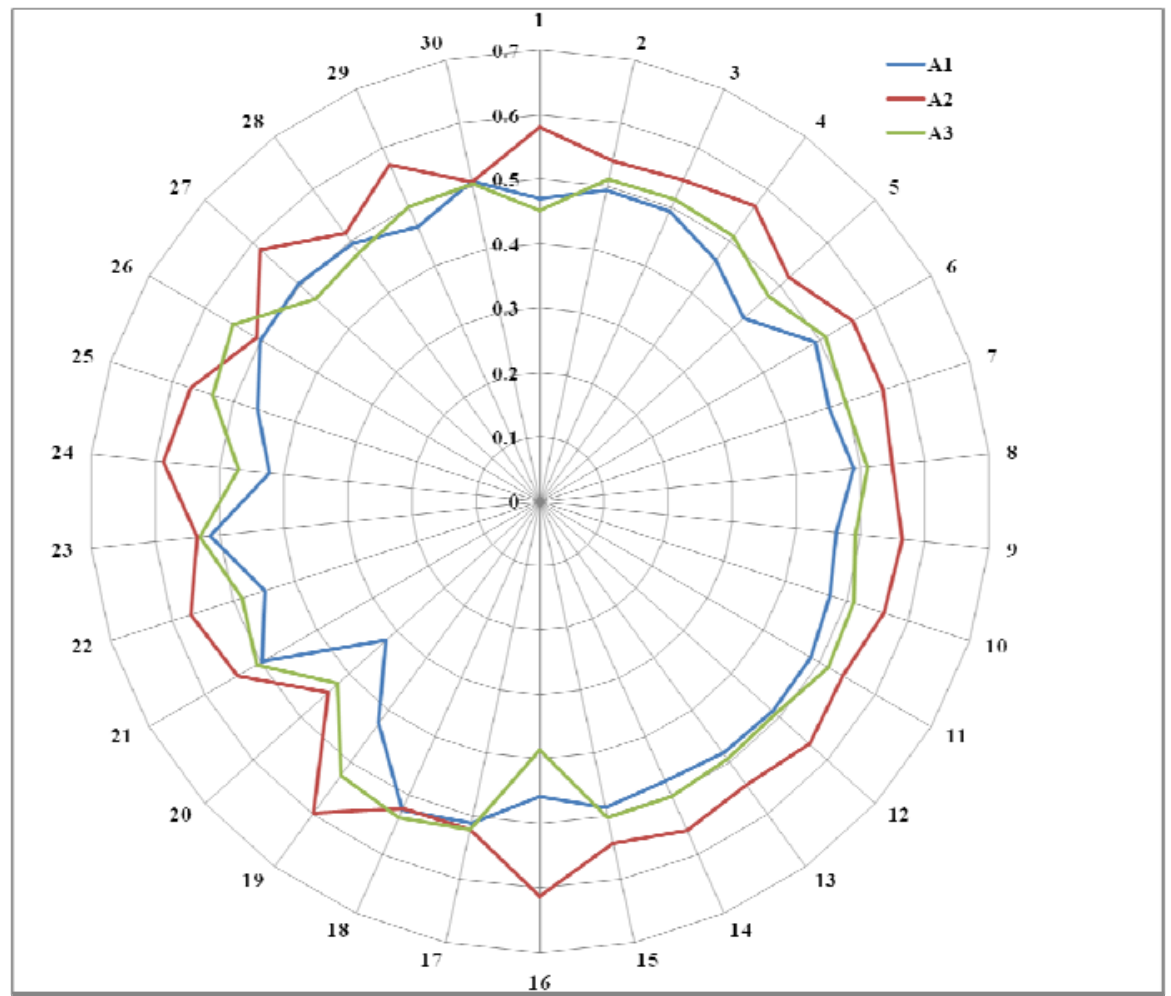

Fig. 8. Sensitivity analysis 


\section{Conclusion}

Equipment selection process is a technique for evaluating the feasible alternatives and selecting the best alternative among a pool of alternatives with respect to criteria under consideration. Therefore, the problem of equipment selection is a multi-criteria decision making (MCDM) issue, because it is influenced by different criteria that are often in conflicting with each other. On the other hand, decision makers are often faced with the uncertainty that plays a significant role in real world problems. Therefore, the MCDM problems are integrated with fuzzy to handle the inherent uncertainty. Fuzzy MCDM has demonstrated its capability and effectiveness in the solution of real world decision making problems.

The main objective of this paper is to propose an integrated model based on FAHP and FTOPSIS under group decision making for evaluating the different types of handling equipment with regard to tangible and intangible criteria in order to select the best candidate among a set of alternatives. Firstly, FAHP is utilized for calculating the relative importance of the evaluation criteria, then; FTOPSIS is applied for ranking alternatives. The weights derived from FAHP are involved in the process of the handling equipment selection by using them in the FTOPSIS computations. Finally, alternatives are ranked in descending order and the alternative with the top score is selected as the first choice. The strength of the proposed model is the ability to evaluate and rank alternatives under partial and/or even lack of quantitative information. A real world case study is illustrated to demonstrate the potential application of the proposed model.

\section{Acknowledgement}

The authors would like to acknowledge the financial support of University of Tehran for this research.

\section{References}

Ahari, S.Gh., Ghaffari-Nasab, N., Makui, A., Ghodsypour, S.H., (2011). A portfolio selection using fuzzy analytic hierarchy process, A case study of Iranian pharmaceutical industry. International Journal of Industrial Engineering Computations 2, 225-236.

Awasthi, A., Chauhan, S.S., Omrani, H., Panahi, A., (2011). A hybrid approach based on SERVQUAL and fuzzy TOPSIS for evaluating transportation service quality. Computers \& Industrial Engineering 61(3), 637-646.

Aydogan, E.K., (2011). Performance measurement model for Turkish aviation firms using the roughAHP and TOPSIS methods under fuzzy environment. Expert Systems with Applications 38, 39923998.

Bao, Q., Ruan, D., Shen, Y., Hermans, E, Janssens, D., (2012). Improved hierarchical fuzzy TOPSIS for road safety performance evaluation. Knowledge-Based Systems, in Press.

Boender, C.G.E., de Grann, J.G., Lootsma, F.A., (1989). Multicriteria decision analysis with fuzzy pairwise comparison. Fuzzy Sets and Systems 29, 133-143.

Buckley, J.J., (1985). Fuzzy hierarchical analysis, Fuzzy Sets and Systems 17, 233-247.

Chang, D.Y., (1996). Applications of the extent analysis method on fuzzy AHP, European Journal of Operational Research 95, 649-655.

Fouladgar, M.M., Yazdani-Chamzini, A., Lashgari, A., Zavadskas, E.K., Turskis, Z., (2012a). Maintenance strategy selection using AHP and COPRAS under fuzzy environment. International journal of strategic property management 16(1), 85-104.

Fouladgar, M.M., Yazdani-Chamzini, A., Zavadskas, E.K., (2011). An integrated model for prioritizing strategies of the Iranian mining sector. Technological and Economic Development of Economy 17, 459-483.

Fouladgar, M.M., Yazdani-Chamzini, A., Zavadskas, E.K., (2012b). Risk Evaluation of Tunneling Projects. Archives of civil and mechanical engineering, in press. doi,10.1016/j.acme.2012.03.008 
Fouladgar, M.M., Yazdani-Chamzini, A., Zavadskas, E.K., Moini, S.H.H., (2012c). A new hybrid model for evaluating the working strategies, Case study of Construction Company. Technological and Economic Development of Economy 18(1), 165-191.

Hwang, C.L., Yoon, K., (1981). Multiple attributes decision making methods and applications. Berlin, Springer.

Kaya, T., Kahraman, C., (2011). Multicriteria decision making in energy planning using a modified fuzzy TOPSIS methodology. Expert Systems with Applications 38(6), 6577-6585.

Kulak, O., Durmusoglu, B., Kahraman, C., (2005). Fuzzy multi-attribute equipment selection based on information axiom. Journal of Materials Processing Technology 169, pp. 337-345.

Lai, H.L., Chen, T.Y., (2011). A fuzzy risk-assessment method using a TOPSIS approach based on interval-valued fuzzy numbers. Journal of the Chinese Institute of Industrial Engineers 28(6), 467484.

Lashgari, A., Fouladgar, M.M., Yazdani-Chamzini, A., Skibniewski, M.J., (2011). Using an integrated model for shaft sinking method selection. Journal of Civil Engineering and Management 17, 569580.

Liao, Ch.N., Kao, H.P., (2011). An integrated fuzzy TOPSIS and MCGP approach to supplier selection in supply chain management. Expert Systems with Applications 38(9), 10803-10811.

Monjezi, M., Bahrami, A., Varjani, A.Y., Sayadi, A.R., 2011. Prediction and controlling of flyrock in blasting operation using artificial neural network. Arab J Geosci 4, 421-425.

Moradi, J.S., Rafeierad, D., Ahari, A.N., (2011). A fuzzy TOPSIS method to rank effective fuel reduction factors, A case study of aviation companies. Management Science Letters 1 (2011) 493502

Naghizadeh, A., Mahvi, A.H., Jabbari, H., Derakhshani, E., Amini, H., 2011. Exposure Assessment to Dust and Free Silica for Workers of Sangan Iron Ore Mine in Khaf, Iran. Bull Environ Contam Toxicol.

Parsaei, S., Keramati, M.A., Zorriassatine, F., Feylizadeh, M.R., (2012). An order acceptance using FAHP and TOPSIS methods, A case study of Iranian vehicle belt production industry. International Journal of Industrial Engineering Computations 3, 211-224.

Saaty, T. L. (1980). The Analytical Hierarchy Process. New York, McGraw-Hill. 28

Sayadi, A. R., Lashgari, A., Paraszczak, J., (2012). Hard-rock LHD cost estimation using single and multiple regressions based on principal component analysis. Tunnelling and Underground Space Technology 27(1), 133-141.

Sule, D.R. (1994). Manufacturing facilities, Location, planning and design (2nd ed.). Boston, PWS Publishing Company.

Sun, Ch.Ch., Lin, G.T.R., (2009). Using fuzzy TOPSIS method for evaluating the competitive advantages of shopping websites. Expert Systems with Applications 36, 11764-11771.

Torlak, G., Sevkli, M., Sanal, M., Zaim, S., (2011). Analyzing business competition by using fuzzy TOPSIS method, An example of Turkish domestic airline industry. Expert Systems with Applications 38(4), 3396-3406.

Van Laarhoven, P.J.M., Pedrycz, W., (1983). A fuzzy extension of Saaty’s priority theory, Fuzzy Sets and Systems 11, 229-241.

Yazdani-Chamzini, A., Yakhchali, S.H., (2012). Tunnel Boring Machine (TBM) selection using fuzzy multicriteria decision making methods. Tunnelling and Underground Space Technology, in press. doi,10.1016/j.tust.2012.02.021

Yu, V.F., Hu, K.J., (2010). An integrated fuzzy multi-criteria approach for the performance evaluation of multiple manufacturing plants. Computers \& Industrial Engineering 58, 269-277.

Yu, X., Guo, Sh., Guo, J., Huang, X., (2011). Rank B2C e-commerce websites in e-alliance based on AHP and fuzzy TOPSIS. Expert Systems with Applications 38 (4), 3550-3557.

Zadeh, L.A., (1965). Fuzzy sets, Information and Control 8 (1965) 338-353.

Zouggari, A., Benyoucef, L., (2012). Simulation based fuzzy TOPSIS approach for group multi-criteria supplier selection problem. Engineering Applications of Artificial Intelligence 25(3), 507-519. 